\title{
PEMBELAJARAN TEKNOLOGI KOMPUTER BIDANG PERKANTORAN BAGI PERANGKAT DESA DI KECAMATAN BUNTU PANE
}

\author{
Novica Irawati ${ }^{1}$, Hommy D.E Sinaga ${ }^{2}$, Mohd Siddik ${ }^{3}$ \\ ${ }_{1,2,3}$ Sistem Informasi, Stmik Royal \\ Email: ${ }^{1}$ novicairawati11@gmail.com, ${ }^{2}$ omisinaga@yahoo.com, \\ ${ }^{3}$ mohd_siddik@gmail.com
}

\begin{abstract}
Abstrak: Computer technology more and more influential in the management of office space at the moment. It is characterized by the more easy it is bureaucracy, the study of grammar of the easy access to information from one point to another. Of course, computer technology will not be such a big contribution to the development of the management of the Government if the role of human resources is not optimized. With respect to the development of computer technology, until now has been a significant development occurred in several areas in regard of the IT application in management offices. Contradictory with the above example, there are still many areas that still have not had the courage or good faith to apply IT in the management of this Office for various reasons. In fact, the IT deployment in government management office management in particular can be a motivation for employees to improve productivity of work.
\end{abstract}

Key Words : Computer technology, management offices, government

Abstrak: Teknologi Komputer semakin banyak berperan dalam manajemen perkantoran saat ini. Hal ini ditandai dengan semakin mudahnya birokrasi tata persuratan, semakin mudahnya akses informasi dari satu titik ke titik lainnya. Tentu saja, teknologi komputer tidak akan sedemikian besar kontribusinya bagi perkembangan manajemen pemerintahan jika peran sumber daya manusia tidak dioptimalkan. Sehubungan dengan perkembangan teknologi komputer, hingga saat ini telah terjadi perkembangan yang signifikan di beberapa daerah dalam kaitan aplikasi TI dalam Manajemen Perkantoran. Kontradiktif dengan kalimat di atas, masih banyak pula daerah perkantoran didesa yang masih belum memiliki keberanian atau itikad baik untuk mengaplikasikan TI dalam manajemen perkantoran ini dengan berbagai alasan. Padahal, pengaplikasian TI dalam manajemen pemerintahan khususnya manajemen perkantoran dapat menjadi motivasi bagi pegawai untuk meningkatkan produktivitas kerjanya.

Kata Kunci: teknologi komputer, manajemen perkantoran, pemerintahan

\section{PENDAHULUAN}

Perangkat desa merupakan salah satu unsur pemerintahan desa yang kinerjanya haruslah dapat bermanfaat dan menjadi tonggak kehidupan pemerintahan desa. Dalam era globalisasi sekarang kini dimana teknologi terutama komputer berkembang sangat pesat di seluruh penjuru Indonesia tidak terkecuali di desa - desa Kecamatan Buntu Pane, Asahan. Dengan adanya alasan tersebut maka perangkat desa wajib dan harus mengikuti teknologi yang berkembang, kesadaran akan pentingnya teknologi terutama komputer sebagai penunjang kegiatan pemerintahan desa untuk mengurus administrasi maupun berkas-berkas yang diperlukan baik untuk pemerintah maupun untuk masyarakat.

Sejak disahkannya undang undang Nomor 32 tahun 2004 Tentang pemerintahan daerah PP 72 Tahun 2005 tentang desa saat ini amatlah mendesak 
Vol. 2, No. 1, Ags 2018, hlm. 19 - 22

ISSN 2614-7912 (cetak)

ISSN xxxx-Xxxx (online)

Available online at http://jurnal.stmikroyal.ac.id/index.php/jurdimas

untuk meningkatkan kemampuan dan kapasitas para pelayanan masyrakat di tingkat desa. Menyikapi hal tersebut kami selaku Dosen - Dosen dari STMIK royal tergerak melakukan kegiatan pengabdian kepada masyarakat dengan mengusung tema "Pembelajaran Teknologi Komputer Bidang Perkantoran Bagi Perangkat Desa Di kec. Buntu pane, Asahan". Dimana para aparat desa diajarkan untuk memanfaatkan teknologi informasi dan komunikasi melalui jaringan internet. Dengan diadakan pelatihan ini, diharapkan peningkatan kerja bagi perangkat desa ini akan lebih memaksimalkan pelayanan bagi masyarakat desa agar lebih baik dan lebih akurat sehingga wargapun merasa sangat terbantu demikian pula bagi perangkat merasa terbantu dengan penguasaan dibidang IT komputer dalam mengerjakan administrasi desa lebih cepat dan akurat dan memberikan manfaat bagi peningkatan kemajuan desa masingmasing untuk menuju kecamatan Buntu Pane yang lebih maju tentunya.

Dengan diadakan pelatihan peningkatan kerja bagi perangkat desa ini diharapkan akan lebih memaksimalkan pelayanan bagi masyarakat desa agar lebih baik dan lebih akurat sehingga wargapun merasa sangat terbantu demikian pula bagi perangkat desa merasa terbantu dengan penguasaaan dibidang IT komputer dalam mengerjakan dministrasi desa lebih cepat dan akurat.

\section{METODE}

Pengabdian kepada masyarakat di Kantor Lurah Desa Sei Silau Timur, Kecamatan Buntu Pane, Kabupaten Asahan, yang dilaksanakan pada Desember 2017 dengan menggunakan metode penyampaian materi Pembelajaran Teknologi Komputer Bidang Perkantoran, kemudian dilakukan workshop Pembelajaran Teknologi Komputer dipandu oleh ketua tim dan anggota, serta melakukan latihan sebagai evaluasi dari kegiatan akhir yang dilakukan dari Pembelajaran Teknologi Komputer Bidang Perkantoran yang telah disampaikan.

\section{PEMBAHASAN}

Teknologi sebagai suatu bidang yang berkaitan erat dengan ilmu sains dan ilmu kerekayasaan atau ilmu engineering. Dapat disimpulkan bahwa pada dasarnya teknologi bisa disebut memiliki dua dimensi, yaitu dimensi engineering dan juga dimensi science. Kedua dimensi itu akan saling terkati selam perkembangan dan juga penciptaan dari sebuah teknologi, dan tidak bisa terpisahkan. (Simarmata, J 2006).

Sesuai dengan namanya microsoft office, software ini diproduksi oleh perusahaan raksasa bernama Microsoft. Microsoft office pertama kali diperkenalkan pada tahun 1989. Pada tanggal 30 Agustus 1992, Microsoft meluncurkan Microsoft Office versi 3.0. Pada versi tersebut Microsoft Office menyertakan Microsoft Word sebagai pengolah kata, Microsoft Excel sebagai pengolah angka, Microsoft Power Point digunakan sebagai aplikasi presentasi yang handal (arifin johar, 2009). Pada Pengabdian masyarakat ini untuk tahapan awal akan disampaikan materi yang berisi pembuatan mail marge dengan langkah langkah sebagai berikut :

A. Langkah -Langkah Pembuatan Mail Merge

Ada 2 dokumen yang digunakan dalam membuat mail merge, yaitu:

1. Dokumen Master, dokumen utama yang isinya sama untuk semua penerima.

2. Data Source, yaitu dokumen yang isinya khusus untuk masing-masing penerima, misalnya nama dan alamat penerima. 
Vol. 2, No. 1, Ags 2018, hlm. 19 - 22

ISSN 2614-7912 (cetak)

ISSN xxxx-xxxx (online)

Available online at http://jurnal.stmikroyal.ac.id/index.php/jurdimas

Data source dapat berupa data di Excel, Access, Contact pada Outlook dan sebagainya.

Berikut adalah langkah untuk membuat data source :

1. Membuat Data Source

Buat data source Nama dan Alamat di Excel seperti contoh di bawah ini dan simpan dengan nama Data Surat.

\begin{tabular}{|l|l|l|}
\hline \multicolumn{1}{|c|}{ A } & \multicolumn{1}{c|}{ B } \\
\hline 1 & Nama & Alamat \\
\hline 2 & Anita & Bali \\
\hline 3 & Ann & Bandung \\
\hline 4 & Benyamin & Jakarta \\
\hline 5 & Pristina & Medan \\
\hline
\end{tabular}

Gambar 1 tabel database

2. Membuat Dokumen Master

Buat dokumen master surat di Word seperti contoh di bawah ini dan simpan dengan nama Master Surat.

3. Menggabungkan Data Source Dengen Dokumen Master

Adapun langkah - langkah penggabungan dokumen master sebagai berikut :

1. Pada Mailings tab, grup Start Mail Merge, klik Start Mail Merge.

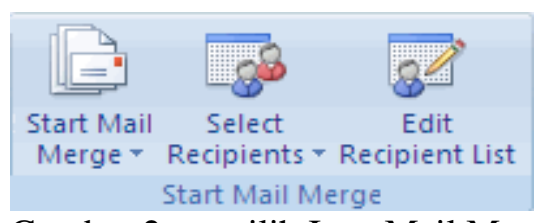

Gambar 2 memilih Icon Mail Merge

2. Selanjutnya kita akan memilih data source.

3. Pada Mailings tab, grup Start Mail Merge, klik Select Recipients.

4. Pilih Use Existing List, dan cari lokasi dokumen (Data Surat) pada kotak dialog Select Data Source. Kemudian klik Open untuk menampilkan kotak dialog Select Table.
5. Pada kotak dialog Select Table, klik lembar kerja yang berisi sumber data dan pastikan kotak First row of data contains column headers dicentang. Kemudian klik OK.

6. Sekarang kita akan menempatkan data pada masing-masing tempatnya.

7. Taruh di kursor di bawah tulisan Kepada Yth., kemudian pada Mailings tab, grup Write \& Insert Fields, klik Insert Merge Field dan pilih Nama.

8. Lakukan juga hal yang sama pada Alamat dan sekarang tampilan dokumen akan seperti contoh di bawah ini. Data ditampilkan dalam tanda kurung siku dua $<<$ data field $>>$.

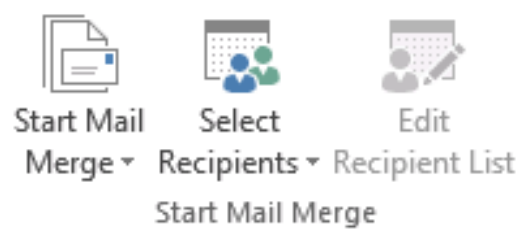

Gambar 3 Tampilan Mail Merge recipent

9. Untuk melihat hasil penggabungan, klik tombol Preview Results. Surat akan ditampilkan per data. Klik tanda panah untuk berpindah antar data.

Jika masih ada yang ingin diubah, klik lagi tombol Preview Results dan lakukan perubahan yang diinginkan. Seperti terlihat pada gambar 4.

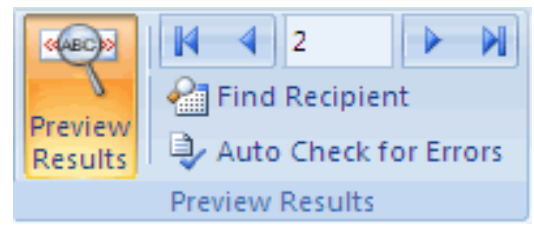

Gambar 4 Preview Result - Mail Merge

B. Menyimpan dan Mencetak Mail Merge

Pada tahap ini, klik tombol Finish \& Merge dan pilih Print Documents, untuk mencetak surat. Ada 3 pilihan:

1. All untuk mencetak semua surat. 
Vol. 2, No. 1, Ags 2018, hlm. 19 - 22

ISSN 2614-7912 (cetak)

ISSN xxxx-xxxx (online)

Available online at http://jurnal.stmikroyal.ac.id/index.php/jurdimas

2. Current record untuk mencetak surat pada halaman yang aktif.

3. Isi nomor urut data pada kotak From dan To, untuk mencetak surat yang dipilih saja.

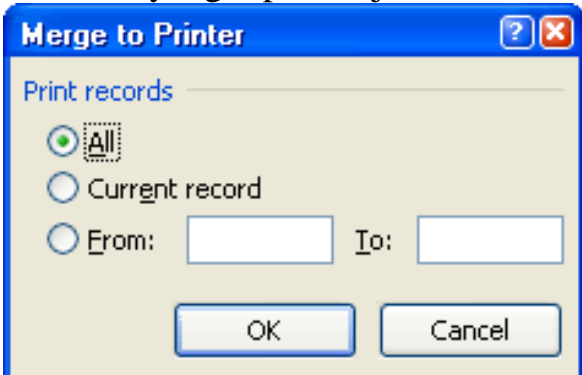

Gambar 5. tampilan mail marge pointer

4. Edit Individual Documents, untuk menyimpan hasil penggabungan ke dokumen baru. Pilihan sama dengan di atas (All, Current record dan nomor urut tertentu). Pada dokumen baru, setiap surat akan ditampilkan per halaman. Jangan lupa menyimpan dokumen baru tersebut

\section{Pengenalan Microsoft Excel Sebagai} Pengolahan Angka

Pada pelaksanaan kegiatan PkM, Tim memaparkan materi tentang Microsoft Excel, para perangkat desa mengikuti paparan materi dan mempraktekan sesuai modul yang disediakan dengan dipandu oleh anggtota tim. Pada awal pertemuan dikenalkan lembar kerja Microsoft Excel. Rangkuman materi tentang pengenalan lembar kerja Microsoft Excel seperti terlihat pada gambar 6 dibawah (Susandra, 2017).

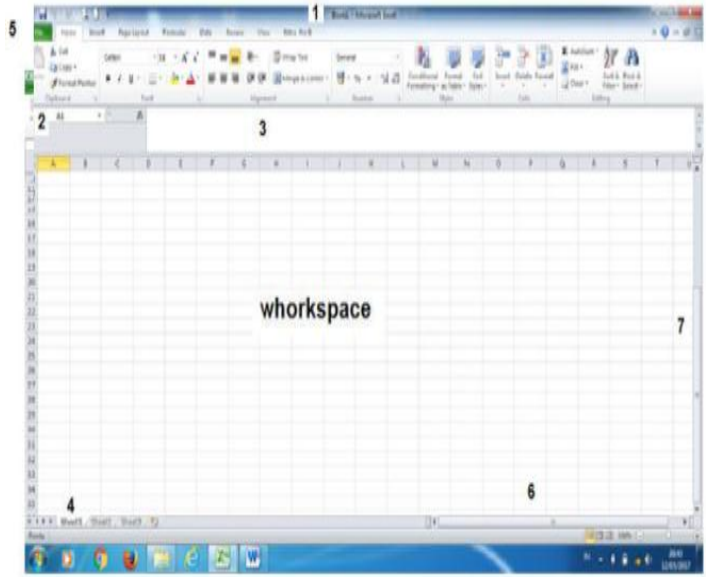

Gambar 6. dibawah

Keterangan:

1. Nama workbook untuk memberi nama pada workspace yang akan disimpan.

2. Alamat sel posisi kusor.

3. Untuk menempatkan formula

4. Worksheet

5. Toolbar file

6. Scrool bawah

7. Scrool samping

Untuk memasukkan data ke dalam Microsoft Excel, dilakukan dengan prosedur sebagai berikut:

1. Pilih sel yang akan diisi dengan menggunakan mouse atau keyboard (tombol kursor)

2. Setelah sel terpilih, ketikkan data yang ingin dimasukkan

3. Setelah selesai, tekan tombol Tab atau Enter. Jika tombol Tab ditekan, kursor akan

2. berpindah ke sel berikutnya. Jika tombol Enter ditekan, kursor akan pindah satu

3. baris ke bawah

4. Jika diinginkan untuk tetap berada di sel yang bersangkutan, jangan tekan tombol

5. Tab atau Enter, tetapi klik pada simbol v di sebelah kiri Formula Bar.

Gambar 7 dibawah menampilkan formula bar fasilitas rumus-rumus matematika yang tersedia. 


\section{Jurdimas (Jurnal Pengabdian Kepada Masyarakat) Royal}

Vol. 2, No. 1, Ags 2018, hlm. 19-22

ISSN 2614-7912 (cetak)

ISSN xxxx-xxxx (online)

Available online at http://jurnal.stmikroyal.ac.id/index.php/jurdimas

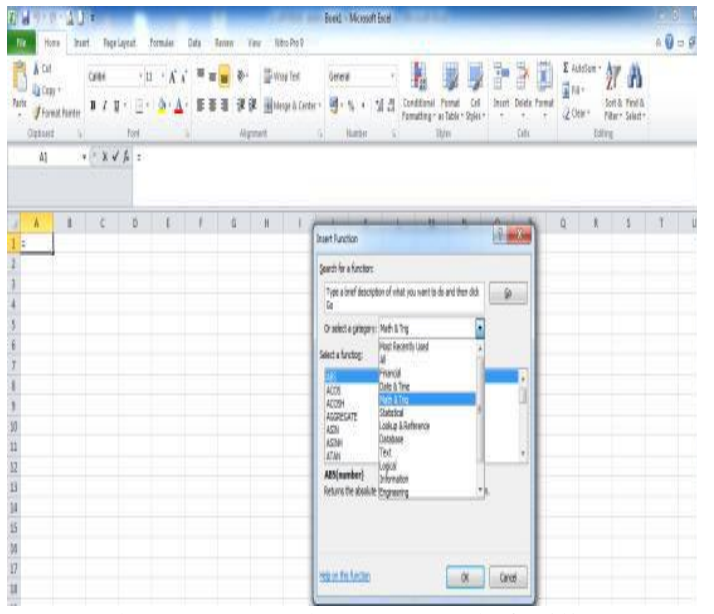

Gambar 7 Formula Bar untuk fasilitas rumus-rumus matematika

Pada saat praktek, tim dosen dan anggota memandu peserta perangkat desa untuk mengoperasikan aplikasi Microsoft Word dan Excel. Gambar 8 hingga Gambar 10 menampilkan dokumentasi pelaksanaan kegiatan Pengabdian Kepada Masyarakat oleh perangkat desa kecamatan Buntu Pane.

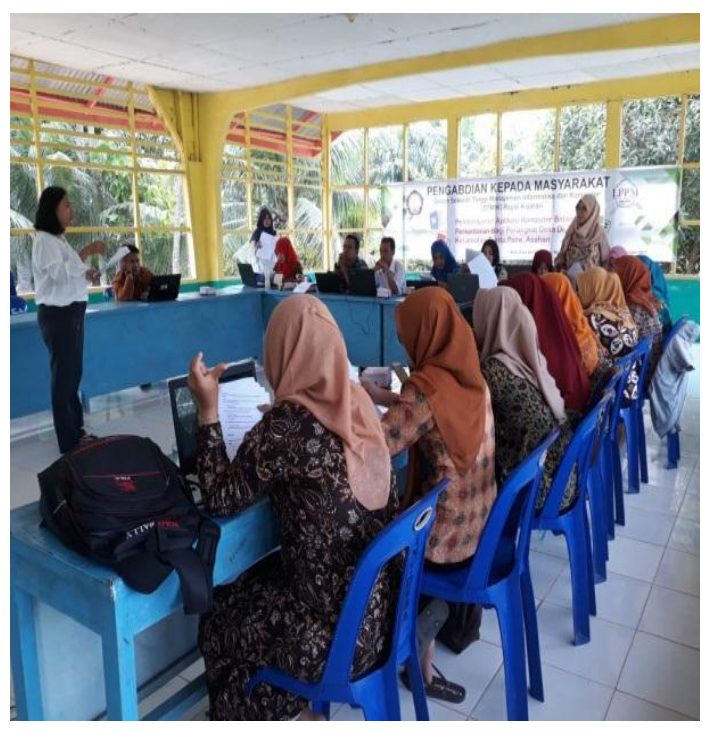

Gambar 8 Penyampaian materi oleh tim narasumber pengabdian

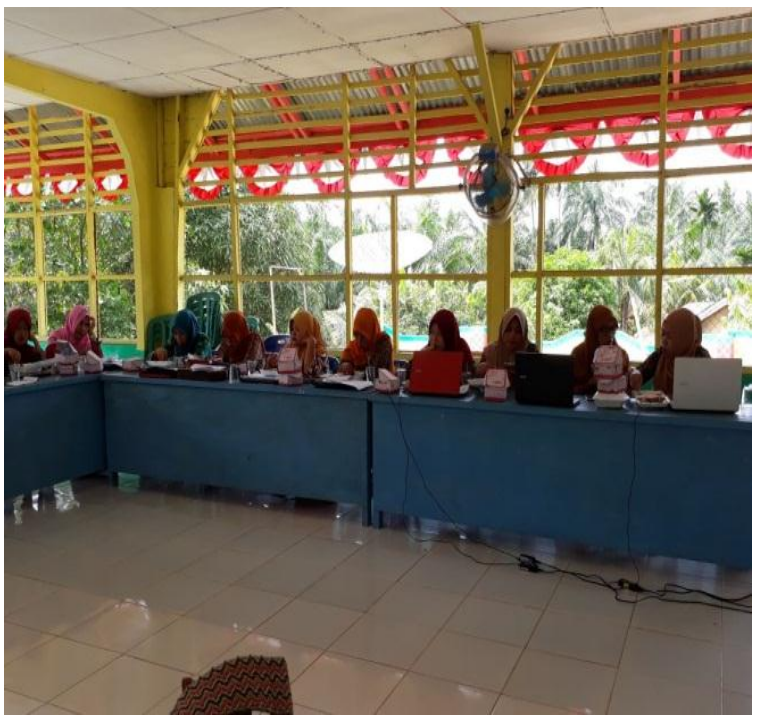

Gambar 9 Para Peserta Perangkat Desa Serius Mengikuti Kegiatan

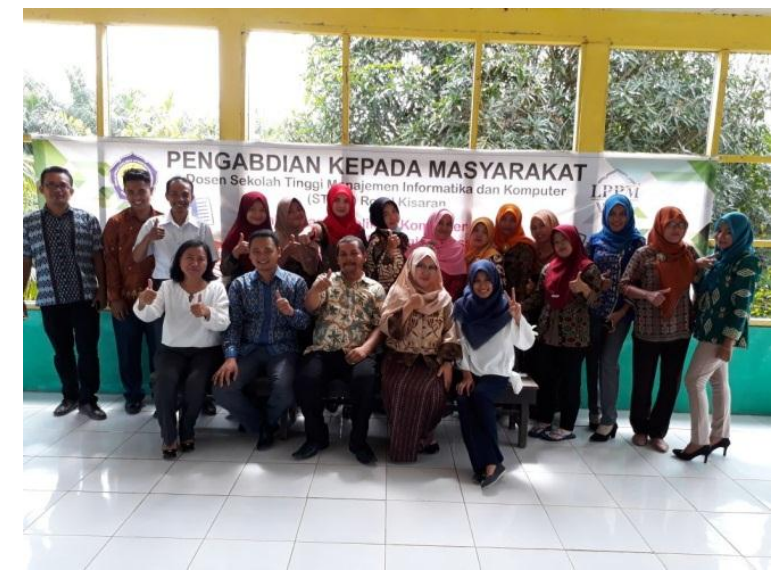

Gambar 10 Foto Bersama Setelah Selesai Melakukan Kegiatan

\section{SIMPULAN}

Dengan diadakannya kegiatan pengabdian kepada masyarakat dalam bidang perkantoran untuk para staf administrasi desa, maka dapat disimpulankan, meningkatnya produktifitas serta kualitas sumber daya manusia para peserta pelatihan. Peningkatan kualitas peserserta meliputi dapat membuat surat massal (mail marge) sehingga tidak perlu melakukan pengetikan berulang-ulang untuk membuat surat massal, melakukan 
Vol. 2, No. 1, Ags 2018, hlm. 19 - 22

ISSN 2614-7912 (cetak)

ISSN xxxx-xxxx (online)

Available online at http://jurnal.stmikroyal.ac.id/index.php/jurdimas

pengolahan angka utnuk dengan menggunakan ms excel dengan mudah, serta membuat slide presentasi untuk mempresentasikan laporan.

\section{UCAPAN TERIMA KASIH}

Kegiatan pengabdian kepada masyarakat ini dapat terlaksana berkat dukungan dari berbagai pihak. Oleh karena itu dalam kesempatan ini, kami menyampaikan banyak terimakasih kepada :

1. Bapak Anda Putra Lubis, SE; M.MA, selaku Ketua Yayasan Pendidikan Royal Teladan Asahan, yang banyak memberi dukungan moril dan materi.

2. Bapak Ruslan Sitorus Selaku Camat Buntu Pane yang telah memberi kesempatan kepada kami untuk mealakukan kegiatan tersebut.

3. Seluruh Perangkat desa yang telah meluangkan waktu untuk mengikuti kegiatan pembelajaran teknologi komputer bidang perkantoran.

\section{DAFTAR PUSTAKA}

Ali, M. (2013). Peningkatan kualitas pendidikan dan pembelajaran melalui teknologi informasi dan komunikasi di universitas negeri Yogyakarta.

Arifin Johar (2009) Dasar - Dasar Menggunakan Microsoft Office, PT. Elex Media Komputindo: Jakarta.

Simarmata, J., \& Paryudi, I. (2006). Basis data. Yogyakarta: Penerbit Andi.

Setyowati, d. (2018). Pemanfaatan microsoft excel untuk pembelajaran matematika dan grafik. Dharma bakti. 